Available online on 15.1.2019 at http://ujpr.org
Universal Journal of Pharmaceutical Research
An International Peer Reviewed Journal
Open access to Pharmaceutical research

\title{
THE PREVALENCE AND PHENOTYPIC CHARACTERIZATION OF EXTENDED-SPECTRUM $\beta$-LACTAMASES-PRODUCING ESCHERICHIA COLI STRAINS ISOLATES RECOVERED FROM TERTIARY HOSPITALS IN SANA'A CITY, YEMEN

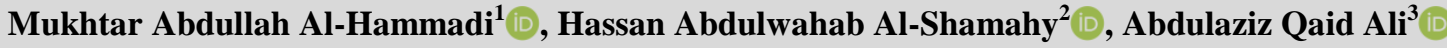 ${ }^{1}$ Department of Medical microbiology, Faculty of Medicine and Health Sciences, University of Sciences and Technology, Hadhramout Branch, Yemen. \\ ${ }^{2}$ Department of Medical microbiology, Faculty of Medicine and Health Sciences, Sana'a University, Sana'a, Yemen. ${ }^{3}$ Department of Medical microbiology, Faculty of Medicine and Health Sciences, University of Sciences and Technology, Sana'a.
}

\section{ABSTRACT}

Objective: The emergence of ESBL producing Escherichia coli in clinical isolates is posing a serious threat for treating nosocomial infections. The aim of the study was to determine the frequency of extended spectrum $\beta$-lactamase (ESBL) producing Escherichia coli isolated from clinical specimens in several teaching and general hospitals in Sana'a city, Yemen, and to compare the phenotypic methods used for the characterization of ESBL producing strains.

Methods: This cross sectional observational study was conducted from $1^{\text {st }}$ July to $28^{\text {th }}$ of August 2017 , at the Department of Medical microbiology, Faculty of Medicine and Health Sciences, University of Sciences and Technology in Sana'a city, Yemen. A total number of 3500 various clinical samples were analyzed during the study period. Escherichia coli were identified using API 20E system and ESBL detection was carried out using double-disk synergy test (DDST) and CLSI confirmatory test. Escherichia coli were isolated from 100 samples, out of which $63(63 \%)$ were ESBL producers and $37(37 \%)$ were non-ESBL producers. The gender distribution of ESBL producing Escherichia coli was 35/45 (77.8\%) in males and 28/55 (50.9\%) in females.

Results: Highest frequency of ESBL producing Escherichia coli was detected in sputum (100\%), wounds (83.3\%) and urine $(65.7 \%)$ samples. Comparison of DDST and CLSI confirmatory test showed that $65(65 \%)$ isolates were characterized by DDST and 63 (63\%) using CLSI confirmatory test. All ESBL-positive isolates were susceptible to imipenem, indicating that this agent is the best drug for treating serious infections caused by ESBL-producing E. coli.

Conclusion: In conclusion, the present study shows moderately high frequency of ESBL producing Escherichia coli among patients suffering from sepsis in tertiary hospitals in Sana'a city. DDST was found to be less efficient in ESBL detection as compared to CLSI confirmatory test.

Keywords: Characterization of ESBL, CLSI confirmatory test, Double-disk synergy test (DDST), ESBL producing Escherichia coli.

Article Info: Received 6 November 2018; Revised 8 December; Accepted 31 December, Available online 15 January 2019

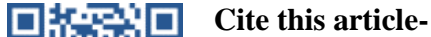

Al-Hammadi MA, Al-Shamahy HA, Ali AQ. The prevalence and phenotypic characterization of extendedspectrum $\beta$-lactamases-producing Escherichia coli strains isolates recovered from tertiary hospitals in Sana'a city, Yemen. Universal Journal of Pharmaceutical Research 2018; 3(6): 23-27.

DOI: https://doi.org/10.22270/ujpr.v3i6.220

Difress for Correspondence

Prof. Hassan A. Al-Shamahy, Faculty of Medicine and Heath Sciences, Sana'a University, P.O. Box 775 Sana'a, Yemen. Phone: +967-770299847, E-mail: shmahe@yemen.net.ye

\section{INTRODUCTION}

The difficulties seen in fighting infections caused by drug resistant organisms, especially those that have acquired resistance to beta-lactams, such as broadspectrum cephalosporins, have resulted from the extensive use of broad-spectrum antibacterial agents. One important resistance mechanism to the betalactams, including new cephalosporins, is due to the destruction of the antibiotics by extended-spectrum beta-lactamases (ESBLs) ${ }^{1}$. Extended-spectrum $\beta$-lact- amases (ESBLs) are plasmid encoded enzymes that hydrolyze $\beta$-lactam ring and cause resistance to $\beta$ lactam antibiotics which include third-generation cephalosporins such as ceftriaxone, ceftazidime, cefotaxime and the monobactam such as aztreonam ${ }^{2}$. The most common ESBLs are derived from widespread broad-spectrum $\beta$-lactamases TEM and SHV. Bacterial strains expressing these $\beta$ lactamases are presenting great therapeutic challenges. In recent years there has been a significant increase in 
incidence and prevalence of ESBL producing bacteria ${ }^{3}$. In addition, Enterobacteriaceae mainly Escherichia coli and Klebsiella species are one of the most bacteria causes sepsis in human ${ }^{1,2}$. High resistance rates to antimicrobials used in the treatment of $E$. coli infections have been reported worldwide, particularly in developing countries including Yemen ${ }^{4}$. Genes responsible for ESBLs production arise by point mutation at the active site of the earlier $\beta$-lactamases (e.g. TEM-1 and SHV-1 enzymes), and they are usually plasmid mediated ${ }^{5,6}$.

In addition, ESBLs-positive Gram-negative bacteria often carry genes that confer high levels of resistance to many other antibiotics (e.g. fluoroquinolones and aminoglycosides) $)^{7,8}$. The epidemiology of antibiotic resistant bacteria, however, varies due to various factors e.g. region, medical field type of infections, and time periods 8,9 . Therefore, identification and determination of antimicrobial susceptibility of bacterial pathogens in the local healthcare setting may aid the clinicians in selecting the appropriate antimicrobial agent (s) to treat infected patients. The aim of the study was to determine the frequency of extended spectrum $\beta$-lactamase (ESBL) producing Escherichia coli isolated from clinical specimens in several teaching and general hospitals in Sana'a city, Yemen, and to compare the phenotypic methods used for the characterization of ESBL producing strains.

Table 1: The association between ESBL $E$. coli isolates and sex and sites of infections.

\begin{tabular}{|c|c|c|c|}
\hline \multirow[t]{2}{*}{ Factors } & \multicolumn{2}{|c|}{ ESBL positive $n=63$} & \multirow[t]{2}{*}{$P$ value } \\
\hline & No & $\%$ & \\
\hline \multicolumn{4}{|c|}{ Sex } \\
\hline Male $n=45$ & 35 & 77.8 & 0.005 \\
\hline Female $n=55$ & 28 & 50.9 & 0.005 \\
\hline \multicolumn{4}{|c|}{ Site of infections (clinical specimens) } \\
\hline Urine $n=67$ & 44 & 65.7 & 0.4 \\
\hline Wounds $n=6$ & 5 & 83.3 & 0.05 \\
\hline Sputum $n=6$ & 6 & 100 & 0.05 \\
\hline Pus $n=9$ & 4 & 44.4 & 0.26 \\
\hline HVS n=5 & 2 & 40 & 0.27 \\
\hline Blood $n=4$ & 2 & 50 & 0.58 \\
\hline $\begin{array}{l}\text { Others specimens } \\
\mathrm{n}=3\end{array}$ & 0 & 0 & 0.02 \\
\hline
\end{tabular}

\section{SUBJECTS AND METHODS}

An active surveillance cross sectional study was conducted at the Department of Medical Microbiology, Faculty of Medicine and Health Sciences, University of Sciences and Technology in Sana'a city, Yemen. The population of the study included in-patients admitted to three tertiary hospitals in Sana'a city: namely: University of Sciences and Technology Hospital, AlJumhori hospital, and Al-Kuwait hospital, from $1^{\text {st }}$ July to $28^{\text {th }}$ of August 2017. A total number of 3500 various clinical samples were analyzed during the study period. The samples were cultured on solid media as Blood, Chocolate and MacConkey agar. Cystine Lysine Electrolyte Deficient Medium (CLED) was used only for urine culture samples. Escherichia coli were identified by colonial morphology, Gram's stain, catalase test, oxidase test and API 20E system (bioMerieux). A seven digit number generated on the basis of various biochemical reactions of API 20E system was checked by API 20E software to confirm Escherichia coli ${ }^{\mathbf{1 0}}$.

\section{Antimicrobial Drug Susceptibility Testing}

A bacterial suspension of Escherichia coli was made according to the $0.5 \mathrm{McF}$ arland turbidity standard and an even lawn of bacteria was made on the Mueller Hinton agar petri plate $(90 \mathrm{~mm})$. The screening for ESBL Escherichia coli was performed using ceftazidime $(30 \mu \mathrm{g})$ disk and ceftazidime resistant strains were considered as screen positives. DDST was performed by using disks containing amoxicillin/ clavulanate on Mueller-Hinton agar plate at a $20 \mathrm{~mm}$ distance from the indicator drugs; ceftazidime $(30 \mu \mathrm{g})$ and cefotaxime $(30 \mu \mathrm{g})$. ESBL production was seen by the clavulanate mediated enhancement of the activity of the indicator drug as a keyhole effect ${ }^{11}$. The CLSI confirmatory tests were performed using disks of ceftazidime $(30 \mu \mathrm{g})$ and cefotaxime $(30 \mu \mathrm{g})$ alone and in combination with ceftazidime-clavulanate $(30 / 10 \mu \mathrm{g})$ and cefotaxime-clavulanate $(30 / 10 \mu \mathrm{g})$. The CLSI confirmatory test was considered positive when the inhibition zone produced by the disks in combination clavulanate increased $\geq 5 \mathrm{~mm}$ than the disks without the clavulanate. The results of double disk diffusion test and CLSI test were compared.

\section{Ethical Consideration}

Ethical clearance for the study was taken from the Faculty of Medicine and Health Sciences, University of Sciences and Technology Research Review Committee. A written permission was also taken from the administrative Managers of the included hospitals.

\section{Statistical analysis}

The analysis of data was done by Epi Info version 6 statistical program (CDC, Atlanta, USA), where the chi-square $\left(\chi^{2}\right)$ and probability value $(p)$ was calculated for the test of significance.

\section{RESULTS}

The detailed results of this study are presented in 3 Tables. Escherichia coli were isolated from 100 culture positive samples, out of which $63(63 \%)$ were ESBL producers and $37(37 \%)$ were non-ESBL producers (Table 2). The frequency of ESBL producing 
Escherichia coli in male and female patients was $35 / 45(77.7 \%)(p=0.005)$ and $28 / 55(51 \%)$, respectively. Occurrence of ESBL producing $E$. coli was found to be highest in the sputum samples 6/6 $(100 \%) \quad(p=0.05)$ followed by the wound samples $5 / 6(83.3 \%)(0.05)$, while in urine samples occurrence of ESBL producing E. coli was 44/67 (65.7\%) (Table 1). Antibiotic sensitivity test result for isolated Escherichia coli is presented in Table 3. All ESBLpositive isolates were susceptible to imipenem, indicating that this agent is the best drug for treating serious infections caused by ESBL-producing E. coli.

Table 2: Comparison of DDST and CLSI detection of ESBL $(n=100)$.

\begin{tabular}{llllll}
\hline \multicolumn{1}{c}{ Tests } & \multicolumn{2}{c}{ Positive isolates } & & \multicolumn{2}{c}{ Negative isolates } \\
\cline { 2 - 3 } \cline { 5 - 6 } & No & \% & & No & \% \\
\hline Double Disk Synergy test & 65 & 65 & & 35 & 35 \\
CLSI confirmatory test & 63 & 63 & & 37 & 37 \\
\hline
\end{tabular}

Table 3: The percentages of antimicrobial resistance detected among 100 multidrug-resistant $E$. coli isolates.

\begin{tabular}{lcc}
\hline \multicolumn{1}{c}{ Antimicrobial agent $(\boldsymbol{\mu g})$} & Number & Percentage \\
\hline Amikacin $(30 \mu \mathrm{g})$ & 6 & 6 \\
Amoxicillin-Clavulanic Acid $(30 \mu \mathrm{g})$ & 96 & 96 \\
Aztreonam $(30 \mu \mathrm{g})$ & 72 & 72 \\
Cefepime $(30 \mu \mathrm{g})$ & 81 & 81 \\
Cefepime-Clavulanic Acid $(30 \mu \mathrm{g})$ & 91 & 91 \\
Cefotaxime $(30 \mu \mathrm{g})$ & 85 & 85 \\
Ceftazidime $(30 \mu \mathrm{g})$ & 87 & 87 \\
Ceftazidime-ClavulanicAcid $(30 \mu \mathrm{g})$ & 97 & 97 \\
Ceftriaxone $(10 \mu \mathrm{g})$ & 84 & 84 \\
Ciprofloxacin $(5 \mu \mathrm{g})$ & 47 & 47 \\
Gentamicin $(10 \mu \mathrm{g})$ & 23 & 23 \\
Imipeneme $(10 \mu \mathrm{g})$ & 0 & 0 \\
Nitrofurantoin $(300 \mu \mathrm{g})$ & 3 & 3 \\
Norfloxacin $(10 \mu \mathrm{g})$ & 50 & 50 \\
Trimethoprim-sulfamethoxazol $(25 \mu \mathrm{g})$ & 66 & 66
\end{tabular}

\section{DISCUSSION}

The treatment of infectious diseases is fundamental matter for human health and the daily increase in bacterial resistance has raised patients' costs in recent years. The production of ESBLs is also a major risk to the use of the new generation of cephalosporins. In the last 20 years, the rate of ESBL production by Enterobacteriaceae has raised considerably ${ }^{12,13,14}$. Among Enterobacteriaceae, E. coli is one of the most important causative agents of nosocomial infections ${ }^{15}$ and $E$. coli is one of the most isolated bacteria from inpatients in Sana'a hospitals; therefore, we selected this bacteria for current study. Occurrences of infection effected by extended spectrum beta-lactamase producing $E$. coli have been widely reported all over the world following the widespread use of the expanded spectrum cephalosporins ${ }^{16,17-20}$. In current study, phenotypic screening of ESBL showed that $63 \%$ of $E$. coli isolates were positive for ESBL production. Based on this result, the prevalence of ESBL producing $E$. coli was high. The lower prevalence of ESBLs producing $E$. coli has been reported by a number of previous studies; for example in a study by Ramazanzadeh et al., revealed a $34.8 \%$ ESBL positive rate among strains of Gram-negative bacteria ${ }^{21}$ and Mobasherizadeh et al., showed that among a total of 2035 consecutive clinical isolates identified as $E$. coli in Al-Zahra Hospital in Iran, 898 (44.1\%) and 432 $(21.2 \%)$, were ESBL producers for hospitalized and non-hospitalized patients, respectively ${ }^{22}$. However, the rate of ESBL producing $E$. coli in current study roughly similar to that reported by Bazzaz et al., ${ }^{23}$ and by Jalalpoor and Mobasherizadeh in Iran which they showed that the prevalence of ESBL positive strains of $E$. coli was $59.2 \%$ and $58 \%$ respectively ${ }^{23,24}$. This varies in prevalence of ESBLs from region to region and from hospital to another is uncertain whether this is because of the differences in infection control practices between hospitals or to differences in the use of new cephalosporins ${ }^{16}$. Current study, has also demonstrated that the rates of ESBLs production in Yemen are similar to that of other countries in our area and the world, such as; India (57.1\%), Turkey (57\%) and published data from European countries, such as; France, Italy, the Netherlands, Germany, and Spain, as well as in the United States, Australia, Japan, Tanzania, Thailand and Pakistan, which showed a higher prevalence of ESBL-producing isolates as in the present study ${ }^{22,25-27}$.

Feizabadi et al., ${ }^{1}$ found that the rates of resistance for ciprofloxacin, cefepime, ceftazidime, and cefotaxime were; $21.4 \%, 28 \%, 76 \%$ and $84.0 \%$, respectively. The comparison of current study results with the abovementioned study shows that antibiotic resistance to four of the previously mentioned antibiotics is higher in current study in which the rates of resistance for ciprofloxacin, cefepime, ceftazidime, and cefotaxime were; $47 \%, 91 \%, 87 \%$, and $85 \%$, respectively. In addition, a high resistance rate for first line drugs including; amoxacillin, and trimethoprimsulfamethoxazole were found in current study $(96 \%$ and $66 \%$ respectively) this result is similar to Mobasherizadeh et al., study, in which both nonhospitalized and hospitalized isolates of E. coli were more resistant to first line drugs including; amoxacillin, 
and trimethoprim-sulfamethoxazole ${ }^{22}$. Current result, which is comparable with other studies in developing countries, is due to the widespread use of these drugs because of their low cost and easy administration. Imipenem, amikacin and Nitrofurantoin were the most effective antibiotics against hospitalized ESBLproducing $E$. coli isolates in our study. All ESBLpositive isolates were susceptible to imipenem, indicating that this agent is the best drug for treating serious infections caused by ESBL-producing E. coli. Our result is similar to that reported by Gholipour et al., and Mobasherizadeh et al., in which all ESBLpositive isolates were susceptible to imipenem, and amikacin $^{22,28}$. The lower rates observed with nitrofurantoin in our study (3\%) may be due to less use of the drug in treating bacterial infections (including UTIs) in Yemen. Newer antibiotics like third generation cephalosporins (e.g. ceftriaxone and cefotaxime) and fluoroquinolones (e.g. ciprofloxacin and norfloxacin) have been more widely used in recent years in Yemen. This observation can be supported by the findings of the present investigation of high resistance rates to ciprofloxacin, cephalosporins such as ceftazidime, ceftriaxone, and cefepime among $E$. coli (Table 3). The comparison of DDST and CLSI confirmatory test showed that the higher numbers of positive isolates were detected by CLSI confirmatory test $(100 \%)$ than the DDST $(95.4 \%)$ (4.6\% were false positive for ELSB) (Table 2). A study conducted by collecting 91 ESBL producers from 32 hospitals in Kinki area of Japan reported DDST positive for $97.80 \%$ of the isolates and was negative for only $2.19 \%$ of isolates. ${ }^{29}$ Rao et al., used DDST and CLSI confirmatory test on 126 ESBL screen positive isolates. Their result of the DDST method detected $86.5 \%$ and the CLSI detected $73.8 \%$ of the cases $^{30}$. Study conducted by Dechen et al., showed that ESBL producers can be detected by DDST and CLSI confirmatory test with equal efficacy. Their results showed $100 \%$ agreement in DDST and CLSI method for detection of ESBL producers ${ }^{31}$. Another study from India reported 135 screen positive ESBL producers. In this study the DDST showed positive results in 126 (93.3\%) while CLSI in $135(100 \%)$ cases $^{32}$. These studies support the results of current study where CLSI confirmatory test is found to be better than DDST.

\section{CONCLUSION}

In conclusion, high frequency of ESBL producing $E$. coli was found at our study. CLSI confirmatory tests generated better results than DDST. Due to the wide spread of ESBL producing strains, it is important to maintain the active surveillance system at microbiological laboratories for early detection of ESBL producing organisms. Preventive measures to stop the colonel spread of the resistant strains could significantly reduce the risk of treatment failure and help in the generation of sound epidemiological data.

\section{ACKNOWLEDGMENTS}

The authors would like to acknowledge Department of Medical microbiology, Faculty of Medicine and Health
Sciences, University of Sciences and Technology in Sana'a city, Yemen for financial support.

\section{AUTHOR'S CONTRIBUTION}

This research work is part of $\mathrm{PhD}$ thesis. The candidate is the first author (MAA) who conducted the laboratory and field works; and wrote up the thesis. The corresponding author (HAA) supervised the laboratory and field works, revised and edited the thesis draft and the manuscript.

\section{CONFLICT OF INTEREST}

No conflict of interest associated with this work.

\section{REFERENCES}

1. Feizabadi MM, Mahamadi-Yeganeh S, Mirsalehian A, Mirafshar SM, Mahboobi M, Nili F, et al. Genetic characterization of ESBL producing strains of Klebsiella pneumoniae from Tehran hospitals. J Infect Dev Ctries 2010; 4(10): 609-15.https://doi.org/10.3855/jidc.1059

2. Kenneth S, Thomson KS, Sanders CC. A simple and reliable method to screen isolates of Escherichia coli and Klebsiella pneumoniae for the production of TEM- and SHV-derived extended spectrum $\beta$-lactamases. Clin Microbiol Infect Dis 1997; 3(5):549-553. https://doi.org/10.1111/j.1469-0691.1997.tb00306.x

3. Bradford PA. Extended-Spectrum $\beta$-Lactamases in the $21^{\text {st }}$ Century: Characterization, Epidemiology, and Detection of this Important Resistance Threat. Clin Microbiol 2001; 14(4):933-951. https://doi.org/10.1128/CMR.14.4.933-951.2001

4. Ghenghesh KS, Rahouma A, Tawil K, Zorgani A, Franka E. Antimicrobial resistance in Libya: 1970-2011. Libyan J Med 2013; 8:20567. https://doi.org/10.3402/ljm.v8i0.20567

5. Bradford PA. Extended-spectrum beta-lactamases in the $21^{\text {st }}$ century: characterization, epidemiology, and detection of this important resistance threat. Clin Microbiol Rev 2001; 14:933-51. https://doi.org/10.1128/CMR.14.4.933-951.2001

6. Pitout JDD, Nordmann P, Laupland KB, Poirel L. Emergence of Enterobacteriaceae producing extendedspectrum $\beta$-lactamases (ESBLs) in the community. $J$ Antimicrob Chemother 2005; 56:52-9.

https://doi.org/10.1093/jac/dki166

7. Paterson DL. Recommendation for treatment of severe infections caused by Enterobacteriaceae producing extendedspectrum $\beta$-lactamases (ESBLs) Clin Microbiol Infect 2000; 6:460-3. https://doi.org/10.1046/j.1469-0691.2000.00107.x

8. Wagenlehner FME, Naber KG. Antibiotics and resistance of uropathogens. EAU Update Ser 2004; 2:125-35. PMID: 30983946

9. Ghenghesh KS, Altomi AS, Gashout S, Abouhagar B. High antimicrobial-resistance rates of Escherichia coli from urine specimens in Tripoli-Libya. Garyounis Med J 2003; 20:8993.

10. Cheesbrough M. District laboratory practice in tropical countries (2) United Kingdom: Cambridge University press; 2000; 124-143.

11. Clinical and Laboratory Standards Institute (CLSI) Performance standards for antimicrobial susceptibility tests. $20^{\text {th }}$ ed. approved standard, CLSI document M100-S20. vol. 30. Wayne, PA: CLSI; 2010.

12. Khorshidi A, Rohani M, Moniri R. The prevalence and molecular characterization of extended-spectrum $\beta$ lactamases-producing Klebsiella pneumoniae isolates recovered from Kashan hospital University, Iran. Jundishapur J Microbiol 2012; 4(4): 289-94. https://doi.org/10.4103/0256-4947.55306

13. Mendes C, Kiffer C, Segura A, Ribeiro J, Turner P. Klebsiella pneumoniae with multiple antimicrobial resistance. Braz J Infect Dis 2004; 8(1): 109-11. https://doi.org/10.15252/emmm.201607336 
14. Putman M, van Veen HW, Konings WN. Molecular properties of bacterial multidrug transporters. Microbiol Mol Biol Rev 2000; 64(4): 672-93. https://doi.org/10.1128/mmbr.64.4.672-693.2000

15. Karimi A, Rahbar M, Fallah F, Navidinia M, Malekan M. Detection of integron elements and gene groups encoding ESBLs and their prevalence in Escherichia coli and Klebsiella isolated from urine samples by PCR method. Afr J Microbiol Res 2012; 6(8): 1806-9. https://doi.org/10.1016/j.ijid.2012.05.587

16. Nasehi L, Shahcheraghi F, Sadat Nikbin V, Nematzadeh SH. PER, CTX-M, TEM and SHV Beta-lactamases in clinical isolates of Klebsiella pneumoniae isolated from Tehran, Iran. Iran J Basic Med Sci 2010; 13(3): 111-8.

17. Branger C, Lesimple AL, Bruneau B, Berry P, LambertZechovsky $\mathrm{N}$. Long-term investigation of the clonal dissemination of Klebsiella pneumoniae isolates producing extended-spectrum beta-lactamases in a university hospital. J Med Microbiol 1998; 47(3): 201-9. https://doi.org/10.1186/1471-2180-10-27

18. Niumsup PR, Tansawai U, Boonkerd N, Polwichai P, Dejsirilert S. Dissemination of extended-spectrum betalactamase-producing Klebsiella pneumoniae and Escherichia coli in Thai hospitals. J Infect Chemother 2008; 14(6): $404-$ 8. https://doi.org/10.1007/s10156-008-0642-z,

19. Pathak A, Marothi Y, Kekre V, Mahadik K, Macaden R, Lundborg CS. High prevalence of extended-spectrum betalactamase-producing pathogens: results of a surveillance study in two hospitals in Ujjain, India. Infect Drug Resist 2012; 5: 65-73 https://doi.org/10.2147/IDR.S30043

20. Wang XR, Chen JC, Kang Y, Jiang N, An SC, Gao ZC. Prevalence and characterization of plasmid-mediated blaESBL with their genetic environment in Escherichia coli and Klebsiella pneumoniae in patients with pneumonia. Chin Med J (Engl) 2012; 125(5): 894-900. PMID: 22490593

21. Ramazanzadeh R, Chitsaz M, Bahmani N. Prevalence and antimicrobial susceptibility of extended-spectrum betalactamase-producing bacteria in intensive care units of Sanandaj general hospitals (Kurdistan, Iran). Chemotherapy 2009; 55(4): 287-92. https://doi.org/10.1159/000224656

22. Mobasherizadeh S, Shokri D, Zargarzadeh AH, Jalalpour S, Ebneshahidi SA, Sajadi M. Antimicrobial resistance surveillance among hospitalized and non-hospitalized extend-spectrum beta-lactamase producing Escherichia coli from four tertiary-care hospitals in Isfahan, Iran; 2008-2011. Afr J Microbiol Res 2012;6(5): 953-9. https://doi.org/10.5897/AJMR11.943

23. Bazzaz BS, Naderinasab M, Mohamadpoor $\mathrm{AH}$, Farshadzadeh Z, Ahmadi S, Yousefi F. The prevalence of extended-spectrum beta-lactamase-producing Escherichia coli and Klebsiella pneumoniae among clinical isolates from a general hospital in Iran. Acta Microbiol Immunol Hung 2009; 56(1): 89-99.

https://doi.org/10.1016/j.sjbs.2014.05.006

24. Jalalpoor S, Mobasherizadeh S. Frequency of ESBLs in Escherichia coli and Klebsiella pneumonia strains isolated from hospitalized and out-patients with urinary tract infection in selective centers in Esfahan (2009-2010). Razi J Med Sci 2011; 18(85): 7-18.

25. Lal P, Kapil A, Das BK, Sood S. Occurrence of TEM and amp; SHV gene in extended spectrum beta-lactamases (ESBLs) producing Klebsiella sp. isolated from a tertiary care hospital. Indian J Med Res 2007; 125(2): 173-8. PMID: 17431288

26. Tasli H, Bahar IH. Molecular characterization of TEM- and SHV-derived extended-spectrum beta-lactamases in hospitalbased Enterobacteriaceae in Turkey. Jpn J Infect Dis 2005; 58(3): 162-7. PMID: 15973008

27. Jeong SH, Bae IK, Lee JH, Sohn SG, Kang GH, Jeon GJ, et al. Molecular characterization of extended-spectrum betalactamases produced by clinical isolates of Klebsiella pneumoniae and Escherichia coli from a Korean nationwide survey. J Clin Microbiol 2004; 42(7): 2902-6. https://doi.org/10.1128/JCM.42.7.2902-2906.2004

28. Gholipour A, Soleimani N, Shokri D, Mobasherizadeh S, Kardi M, et al. Phenotypic and Molecular Characterization of Extended-Spectrum $\quad \beta$-Lactamase Produced by Escherichia coli, and Klebsiellapneumoniae Isolates in an Educational Hospital, Jundishapur J Microbiol 2014 ;7 (10):11758. https://doi.org/10.5812/jjm.11758

29. Komatsu M, Ajhara M, Shimakawa K, Iwasaki M, Nasgasaka Y, Fukuda S, et al. Evaluation of MicroScan ESBL confirmation panel for Enterobacteriaceae producing, extended-spectrum $\beta$-lactamases isolated in Japan. J Diagn Micr Infec Dis 2003;46(2):125-130. https://doi.org/10.1016/S0732-8893(03)00041-5

30. Rao SPN, Basavarajappa KG, Krishna GL. Detection of extended spectrum beta-lactamase from clinical isolates in Davangere. Indian J Pathol Microbiol 2008; 51(4):497-499. PMID: 21321429

31. Dechen CT, Shyamasree D, Luna A, Ranabir P, Takhellambam SKS. Extended Spectrum Beta-lactamase Detection in Gram-negative Bacilli of Nosocomial Origin. J Glob Infect Dis 2009;1(2):87-92. https://doi.org/10.4103/0974-777X.56247

32. Gaurav D. Prevalence of Extended Spectrum Beta Lactamase (ESBL) Producers among Gram Negative Bacilli from Various Clinical Isolates in a Tertiary Care Hospital at Jhalawar, Rajasthan, India. J Clin Diag Res 2012; 6(2):182187.https://doi.org/10.7860/JCDR/2013/6460.3462 